\title{
Micro \& Small Enterprises in Ireland: A Brand Management Perspective
}

\author{
Bobby Kennedy \\ Dept of OPD, School of Business, CIT. Cork. Ireland \\ Dr Angela Wright \\ Senior Lecturer, Dept of OPD, School of Business, CIT. Cork. Ireland \\ E-mail: Angela.Wright@cit.ie
}

Received: January 18, 2016 Accepted: February 4, 2016

doi:10.5296/ber.v6i1.9460 URL: http://dx.doi.org/10.5296/ber.v6i1.9460

\begin{abstract}
Branding aids companies in the acquisition of new customers, allows them to build a favourable reputation, leads to increased customer loyalty and, ultimately, is a driver of profitability. Although there is an impressive quantity of academic literature related to both large corporate and product line branding, there has been less focus regarding the research on branding of small businesses, despite their economic importance.

In the specific case of SMEs in Ireland, branding studies are scant. There is little understanding of the branding practices of SME founder-owners in Ireland, and, moreover, a lack of clarity as to their knowledge levels apropos the strategic brand management process. Essentially, many small business owners may not even realise that their business is a brand, partly due to a lack of understanding of what the concepts of a brand and branding actually mean. This paper presents findings from research associated with the brand development practices of Irish micro and small enterprises. A qualitative data collection tool, leveraging semi-structured interviews is employed to collect substantive and relevant data from 10 Irish micro and small business owners. The study extends the knowledge of the brand development process being undertaken by these companies.

The findings in this study reveal an unfavourable picture in terms of branding practices in Irish SME's and demonstrates a lack of understanding and devotion on behalf of founder-owners towards the process. These conclusions have direct implications for branding literature, specifically in relation to Irish and international SMEs and also for managerial practice within those organisations.
\end{abstract}


Keywords: SME, SME brand, SME branding, Branding, Brand management, Marketing, SME, Corporate branding, crowdsourcing

\section{Introduction}

\section{Customers must recognise that you stand for something}

Howard Schultz, Starbucks,

[in Aaker, 2014: 25].

The importance of branding is well supported by academic research, and brands are generally recognised as assisting companies to build both differentiation and sustainable competitive advantage (Beverland et al., 2007). In a world of fast changing markets, corporate brands are becoming increasingly important for successful companies (Harris and de Chernatony, 2001) with this importance being accentuated by the understanding that a brand is now one of the most valuable assets a firm can own (Abimbola, 2010). There is now a growing level of belief that corporate brands bring increased benefits to companies in ways that product brands do not (Hatch and Schultz, 2003). These benefits do not only apply to larger companies. "Irrespective of their size, and resources, SMEs' compete in an equally competitive environment and one characterised by the same dynamic market trends as for larger firms" (Abimbola, 2001: 99). Branding is therefore not only necessary for very large companies, it is also as important if not more important for smaller organisations (Lamons, 2005).

For the purpose of the research, this study adopts the European Commission (EC) definition of an SME: "an enterprise which employs less than 250 persons and which has an annual turnover not exceeding $€ 50$ million, and/or a balance sheet not exceeding $€ 43$ million" (European Commission, 2003: 5). The importance of these SMEs has been stressed by The EC, who recognise that they represent $99 \%$ of all enterprises, and consequently play a central role in the European economy, acting as a major source of entrepreneurial skills, innovation and employment (European Commission, 2005). The EC have further reported that in Ireland, SMEs are comparatively more prevalent in comparison to the EU average, and in total Irish SMEs account for $50 \%$ of private-sector economic added value, and provide employment for seven out of ten private-sector workers (European Commission, 2013).

Yet, despite their importance, Krake (2005) describes how SMEs are never treated as a separate category in any brand management books or journals. Merrilees (2007) highlights that despite the economic importance of SMEs, much of the research which has been completed to date in relation to branding is usually concerned with large organisations or well known consumer products, with little research carried out in the area of SME branding. Research or literature in this field and in an Irish context is even more limited, with few empirical studies specifically relating to branding in Irish SMEs. This omission presented an opportunity for this research to examine a suitable Irish SME base and, in doing so make a contribution to current knowledge.

The central objective of this research therefore, is to assess the branding practices of 
early-stage micro and small enterprises in Ireland, with the intent of understanding how the founder-owners of these companies approach the strategic brand management process.

\section{Literature Review}

\subsection{SMES}

One of the typical characteristics of an SME "is the often all-controlling and all-deciding role of the owner of the company" (Krake, 2005: 230). Yet, the EC highlights that in order to support the creation and growth of SMEs, "competencies in management are a key determinant to a company's growth potential ... and a crucial determinant of the equation leading to growth, business success or business failure" (European Commission, 2006: 10, 11). This connects with the view of Ropega (2011) who depicts the entrepreneur as the most crucial reason for the failure of a small business and reasons that the motivation, skills and abilities of the owner has a key influence on the overall management of the business. Ropega (2011: 479) cites Bradley and Moore (2000), who discuss that one of the two most prevalent causes of failure in small businesses is "inadequate management skills or poor knowledge of the business" and analogous to this, Smallbone and Wyer, (2000) have examined how the educational level of the entrepreneur can have an impact on the management resources of a firm and the desire and motivation of the owner to grow the business (in Birdthistle et al., 2010). Indeed, there is also risk that the founder-owners may have higher regard for their own abilities than they should have, overestimating "the set of skills and competences at hand, which often paves the way to failure" (Freiling and Laudien, 2013: 2). Yet, Hynes and Richardson, (2007) contend that it is rare for the founder to possess all the necessary skills and instead they are usually predisposed towards technical, product or service knowledge. The additional management and strategic planning skills required need to be developed "to contribute in a meaningful manner in the workplace and for the founder-owners to effectively capitalise on potential business growth opportunities" (2007: 733). Additionally, research also reveals that marketing skills, such as, market research, strategic analysis, product positioning and pricing and promotional strategies "are critical for a successful entrepreneur and a growing small firm” (Ibrahim and Soufani, 2002: 426).

In this regard the EC makes, amongst others, the recommendation that entrepreneurs and heads of SMEs need to adhere to the idea that they should always be proactively seeking additional information, and, in particular, management and marketing knowledge (European Commission, 2006: 29), where successful marketing management should include connecting with customers, shaping the market offerings, delivering and communicating value, and in addition, building strong brands (Kotler and Keller, 2007).

\subsection{Branding in SMEs}

Aaker (2014) depicts a brand as an "evolving relationship based on the perceptions and experiences the customer has every time he or she connects to the brand" (2014: 1). It can also be considered as a collection of associations or feelings people have about a particular product, service, or an organisation, with the tradition of branding meaning the "process of creating the signals that generate these associations" (Adamson 2006: 226). In the past, the 
brands visual identity elements would have been used to drive these signals, however, the current approach to branding also emphasises a focus "on those brand identity characteristics that create its unique story" (Ruzzier et al., 2013:168). In a world of ever increasing levels of marketing messaging, and with more decisions to be made and less time to make them, the ability of a strong brand "to simplify decision making, and reduce risk, is invaluable" (Keller, 2008: 9). The power of a brand therefore, lies in its ability to influence consumer buying behaviour, (Ries and Ries, 2002: xii) and, if managed effectively and consistently, a brand will tell customers and other stakeholders exactly what the business does, and why (Dunn and Davis, 2002). Brands are therefore "increasingly viewed as offering a crucial point of differentiation and a sustainable form of competitive advantage" (Beverland et al., 2007: 394).

Branding is usually considered to be relevant for larger organisations and is frequently overlooked as also being pertinent for smaller businesses (Merrilees, 2007; Bresciani and Eppler, 2010). Challenging this assumption, [Inskip, 2004; Lamons, 2005; Ahonen, 2008; Bresciani and Eppler, 2010] contend that corporate branding as a philosophy is however, just as salient for an SME as it is for a larger company, and that small businesses need brand power as much, if not more, than bigger ones. Yet, despite this, Krake (2005) concludes that within SMEs, brand management receives little focus and "is not given the priority it needs for a strong brand image to be constructed”, (2005: 230-231).

Highlighting the danger in this lack of focus, Wong and Merrilees (2005) argue that if a business simply focuses on selling its product or service, the customer will nonetheless formulate an opinion of the offering and of the firm selling it, and whether that business likes it or not, this becomes the brand, a brand for which the company has had little say in creating, and over which they can exercise little control.

To avoid this harmful outcome, entrepreneurs need to develop a brand strategy, but in practice, since a good branding and communication strategy is not necessary to start a business, entrepreneurs usually concentrate more on financial and production issues, and the importance of branding is quite often overlooked (Bresciani and Eppler, 2010).

\subsection{Strategic Brand Management Process}

A brand strategy is a plan used for your brand idea to deliver on your business strategy, and necessitates understanding what branding signals will best underpin your brand idea (Adamson, 2006). It should include a compelling brand identity and a differentiated position, all designed to resonate with customers. Additionally a brand strategy necessitates the creation of an appropriate organisational structure together with the necessary processes, and in order to ensure they are not at the mercy of 'ad hoc' decisions, someone or some group must be in charge (Aaker and Joachimsthaler, 2009).

Ruzzier et al., (2013) discuss how, when developing a brand identity, a company should not just consider the visual elements of the brand but also take into account those items which can convey invisible elements of a brand. A combination of all these identity elements can allow an SME to create a narrative that will draw attention to the unique positioning of their 


\section{IIMacrothink

brand. After reviewing and combining models by [Kapferer, 1998; Aaker \& Joachimsthaler, 2009; de Chernatony, 2010; Konecnik, Ruzzier \& de Chernatony, 2010], - Ruzzier et al., (2013) suggest a process model incorporating 5 key steps for brand identity development in SMEs:

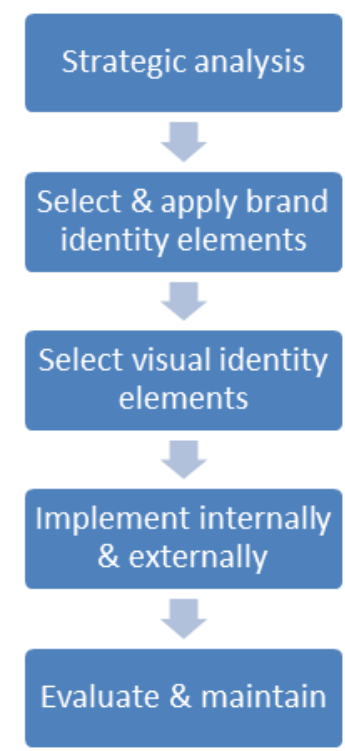

Figure 1. Visualisation of Process Model for Brand Identity Development

[Adapted from (Ruzzier et al., 2013)].

\subsection{Strategic Analysis}

One key to successful brand building is to understand how to develop a brand identity, to know what the brand stands for, and to effectively express that identity (Aaker, 1996). Aaker (2014) advises that the development process starts with context and strategy and requires an in-depth analysis of customer segments, competitors, market trends, environmental forces, the current brand strengths and weaknesses, and the business strategy. Aaker and Joachimsthaler (2009), in support of the need for analysis, identify the need for customer, competitor and self-analysis and Ruzzier et al. (2013) add a fourth pillar of industry sector analysis. Strategic analysis as a theme was subsequently explored by the author under the topics of sector, customer and competitor. For the purposes of the study, and the time limitations to which it was subjected, the author choose to exclude the pillar of company self-analysis and instead focused on external factors only.

\subsection{Brand Identity Elements}

"Corporate branding is not just about a nice logo or compelling advertising, above all, it is concerned with giving an organisation a clear and publicly stated sense of what it stands for" (Inskip, 2004: 358). Because "a brand identity provides direction, purpose and meaning and is central to a brand's strategic vision" (Aaker, 1996: 68), the brand identity should go beyond the visual elements of the brand and invisible elements of the brand, such as "vision, values, personality, benefits, culture and attributes" should also be presented. Only through a combination of these identity elements, will SMEs be able to "create a story that will draw 
attention to the unique position of the brand" (Russier et al., 2013: 172). Indeed Merrilees, (2007) expresses the view that some consideration of corporate identity, values and culture is worthwhile from inception, "even at the pre-launch stage, and these matters can be incorporated into the business model" (2007: 412).

\subsection{Visual Identity Elements}

Ruzzier et al., (2013) explain how visual identity includes those elements which make the brand most visible, how they should reflect the key identity characteristics, and how they will contain elements such as name, symbol (logo), slogan and web domain. These symbols are important because a "strong symbol can provide cohesion and structure to an identity, making it much easier to gain recognition and recollection" (Aaker and Joachimsthaler, 2009: 54). When it comes to brand name, Keller (2008) contends that the selection of a brand name is both an art and a science and like any brand element, it must be chosen with the six general criteria of memorability, meaningfulness, likability, transferability, adaptability and protectability in mind (Keller, 2008: 145, 147). The brand name should therefore, "not be left to chance or the personal preference of individuals in the SME" (Russier et al., 2013: 176).

\subsection{Internal \& External Brand Implementation \& Ongoing Branding Programs.}

Research identifies the importance of the owner manager with reference to the SME brand management system and "it has been found that the founder-owner leads and influences branding within a small enterprise, driving marketing activities according to their competence, knowledge, experience, business style and personal networks [Hill et al., 1999; Glimore et al., 2001; Hill and Wright, 2001; Simpson et al., 2006; Merrilees, 2007: Martin, 2009; O’Dwyer et al., 2009]", (in Mitchell et al., 2012: 162).

Aaker (2014) further describes how powerful brands are built from within the company and to create a strong brand in the marketplace, employees and partners need to understand the brand vision and care about its realisation. In this regard, [Harris \& de Chernatony, 2001; Hatch and Schultz, 2001; Vallaster \& de Chernatony, 2006] have identified the importance of employees in developing a consistent brand image and in helping reduce the gap between the desired brand identity and that which is perceived by other company stakeholders. Because of this importance, Harris and de Chernatony (2001) discuss how managers must help employees understand the types of relationships that are appropriate, including those with other employees, external consumers and other stakeholders, all of which should be based on the brand's core values. Overall, it is advisable not to keep the management of the brand to oneself, but instead, the owner should communicate throughout the entire company how important it is (Krake, 2005).

Keller (2008) describes the importance of the correct choice of brand elements but also emphasises how brand building, channel, \& communication strategies must be put into place in order to "create strong, favourable, and unique brand associations" (Keller, 2008: 40, 220). This external implementation of the brand should include a combination of different marketing mix tools designed to communicate the brand to the target audience, but will generally be "much different in SMEs than in larger companies, because of the SMEs limited 
financial resources", (Ruzzier et al., 2013: 179).

\subsection{Ongoing evaluation and maintenance}

"If we are a good firm, selling a good product and giving a good service, then the brand may well be good - but we cannot be sure of this" (Wong and Merrilees, 2005: 162). Consequently, Bresciani and Eppler (2010), describe how an important guideline is to measure the effect of the branding effort, and to subsequently take any corrective action required to improve the branding strategy in a continuous and iterative process. On the whole, only by examining the brand reputation among stakeholders, will a manager be able to ensure the brand identity is being communicated successfully, and guarantee those outcomes which are valued as being consistently delivered (Harris and de Chernatony, 2001).

\subsection{Summary}

The review so far has provided an understanding of the context in which the study is placed. It has uncovered how much of branding research is about major consumer products or large firms and how comparatively little research about corporate brands in the context of SMEs has been performed. While scholars have conducted a wealth of studies into branding and corporate communication, much of this literature focuses on well-established companies and by contrast, only a small proportion of this literature has explored branding in relation to new ventures or SMEs. Subsequently, the aim of this paper is to focus on this area of brand management practices in an effort to develop a richer and more thoughtful understanding of same.

\section{Methodology}

As the purpose of the study was to build an understanding of the practices of the research subjects during the early stage formation of their companies, the theory building approach of inductive research allowed the researcher to assemble common elements and be better able to formulate theory on the topic. As the study sought to acquire new knowledge in an under-explored subject area, through the collection of substantive and relevant data and opinions, exploratory research was selected as the most relevant for this investigation, as it "asks 'what' and 'why' questions and it is commonly used when new knowledge is sought or certain behaviours and their causes need discovering" (Wisker, 2008: 71-73).

Due to the relevance of the views of each of the participants towards the overall objective of the study, and to increase the richness of the data being gathered, a qualitative approach leveraging semi-structured interviews was an essential tool in achieving the overall research objectives and allowed the researcher to understand and interpret ideas, beliefs and practices amongst the participants (Wisker, 2008). The research was placed in an Irish, non-sector specific context, allowing investigation within the same economic and regulatory environment.

Throughout the semi-structured interview process, answers were sought to the main research question, 'how does the founder owner approach the subject of corporate branding in a micro and small sized enterprise in Ireland, not merely through their words but also through their 
actions?' This main research question was divided into 4 themes and each of these was examined through a number of secondary questions.

In total, the empirical part of this study explored both the perceptions of founder-owners towards corporate brand building in micro and small enterprises, and the practices currently in place in their companies. The analysis and conclusions are based on the research undertaken, representing the totality of the primary and secondary findings. The sample finally consisted of 10 participant founder owners drawn from a variety of sectors including industrial services, industrial research, internet technology, food services and food production and transportation services. All interviewees were founder-owners of their respective micro and small enterprises. All were instrumental in the establishment of the businesses documented, and all were still involved in day-to-day operations. Based on the interview findings, the researcher was able to develop a suggested model for practice for the brand development steps to be undertaken by SMEs. This researcher identifies 11 practical recommendations for branding practice, both from existing studies, and from the findings in this study from which Irish and non-Irish start-up entrepreneurs could benefit from in the future.

\section{Key Findings}

A key element of the approach taken to theory building in this study has been to evaluate the level of brand knowledge amongst each participant. The resultant interviews were analysed around the 4 themes of strategic analysis, brand building, ongoing branding programs and ongoing evaluation and maintenance, with each of these being examined through a number of secondary questions. Results from each of these components are presented here.

\subsection{Evaluation of Knowledge}

The definitions of brand examined for the purposes of this research note functional, emotional, and self-expressive or other social benefits. This research sought to identify how much theoretical knowledge the interviewees had in relation to a brand, and each of the participants was asked for their definition of a brand. The results showed that $70 \%$ of the participants felt that brand was in some way connected to things you did which could be characterised as a functional benefit. Only $40 \%$ however believed that it was connected to emotional or other intangible benefits and the vast majority failed to describe any connection to the consumer mindset and to the manner in which a brand relationship evolves with the consumer. In this regard, of the founder-owners interviewed, only a single interviewee provided a definition that came close to meeting the academic definitions. "You give me a good product that I can trust and I'll give you my loyalty, and a habit loop forms around that". The study finds that there is an incomplete understanding amongst the interviewees of what a brand and branding represents.

\subsection{Strategic Analysis}

This research found that, in total, only $30 \%$ of the 10 participants had performed any strict industry sector analysis prior to the establishment of the business, with $70 \%$ having entered their chosen sector with no strategic analysis behind them. This $70 \%$ sought to pursue their 
venture based solely on a mix of previous experience, necessity, passion or lifestyle or, on a personal belief in the likelihood of success. As described by one business owner 'it wasn't based on research, I would say I stumbled into it but it would be a passion of (co-founder name) and mine anyway".

In relation to customer analysis, all participants claimed to be able to identify their primary customers and were indeed able to provide a description of these to the researcher. Nine out of 10 were able to articulate what they perceived to be a clear value proposition, with $70 \%$ of total participants claiming that there was some form of ongoing research supporting this belief. Nevertheless, from this $70 \%$, only one, equating to $10 \%$ of the total research sample, was conducting any formal measurement, with the remaining $60 \%$ who claimed to conduct further evaluation, performing it purely on an 'ad hoc basis'. "We don't go out and do a survey. We wouldn't have enough people to do that, but talking to people, yes, the product has worked"

When it came to competitor analysis, $80 \%$ of the interviewees claimed to have a good awareness of who their primary competitors were. The remaining $20 \%$ also professed to an understanding, but seemed unsure in their responses, and were unable to provide clarity during the interview process. Yet, of those who claimed to have a good awareness of their competition, only 2 of the 8 could claim to having performed any competitive analysis. "It's absolutely fundamental, the SWOT analysis and everything else, the competitive analysis. .."

\subsection{Brand Building}

"Corporate brand building activities may and should begin even before a company is officially established in the pre-established stage", (Juntunen et al., 2010:130). The second theme of the research process sought to shed light on the question of brand building, whether it was considered, and if so, at what stage of the company development was it introduced. Additionally, where brand building was undertaken amongst the participating companies, the interviews sought to uncover the process employed in terms of the creation of both the brand identity elements and the visual identity elements.

\subsubsection{Timing and Importance}

When asked how important they felt branding was to their business, $100 \%$ of the interviewees expressed a belief in its importance. When it came to the timing of when a brand was initially considered, for $70 \%$, consideration of a brand had been a factor during the inception stage of the business. "Right at the beginning, the same time we were learning to make chocolate. Thinking about the brand, we actually launched the brand itself on social media before we even made a bar of chocolate". For a further $20 \%$ it had been considered during the survival phase.

\subsubsection{Brand Identity Elements}

For brand identity elements, the interviews focused on four main components, mission, vision, values and preferred culture, and sought to understand how far the founder-owner had gone in developing each of these, and whether they were written down and actively shared with staff 
and other stakeholders. Taken as a whole, $90 \%$ of the participating companies claimed to have a mission statement, although only $60 \%$ could claim to have it written down. $80 \%$ claimed to have a vision statement, although an appreciably lower $30 \%$ responded that they had it written down, with the remaining 5 out of the 8 respondents who responded positively, retaining it personally and keeping it unshared.

Ciulla (1999) and Rode and Vallaster (2005), have expressed the view that in "a micro industrial services firm, values are intertwined with the beliefs and experiences of the founder", (in Sandbacka et al., 2013:167). In the current study, 100\% of participants were able to articulate a clear set of business values, which in all cases were closely aligned with the values and belief system of the owners themselves. "Principles guide us. It's our principles of what we've experienced in our lives which guide our business, and our business decisions, and how we deal with people".

The study identified that $70 \%$ of the participants have an opinion of the importance of corporate culture, with $50 \%$ of the total participants able to provide an opinion of the type of culture they would like in their business. Only $20 \%$ expressed a lack of interest in the topic. Of the $50 \%$ of participants who were able to identify the preferred culture for their business, 1 of the 5 had already partially established the culture envisaged, but the remaining 4 could only yet be categorised as having aspiration towards the subject. "The culture is increasingly important. As things grow bigger, it's important that on a project-by-project basis that they feel like they're a team working all in the same direction".

\subsubsection{Visual Identity Elements}

Ninety percent of the participants spoke of some level of analysis having taken place in their consideration of visual identity elements, primarily, name and logo. Contrary, however, to academic advice that the brand name should not be left to chance or to the personal preference of individuals, it was found that $60 \%$ of the owners had been pivotally involved in the selection of the two main identity elements of name and logo, with only $30 \%$ seeking outside help. Of these $30 \%$, following the choice of the name by the founder-owner, often with help of family or friends, only logo design was outsourced. In two of these cases, the same online marketplace design service was used, and, for the third, a family member who was a graphic designer was recruited into the process. One participant shared their experience of the potential challenges created when the owner uses personal preference rather than taking a strategic approach to the name creation process. "The (company name) is probably a bad example of branding . . . I thought it was going to be fun to have (company name). It does not work in any of the markets that we work in".

Three broad themes emerged from the interviews around the process of creating the final logo. The logo was either influenced solely by brand identity elements, solely by product, or by a combination of both. When defining the logo design, 50\% of participants were influenced solely by product where the logo was designed purely as a meaningful indicator of the product offering. In $20 \%$ of the cases, the brand identity elements were taken solely into consideration, and in another $20 \%$ of cases, the logo design was influenced by a combination of both. 
Throughout the course of the interviews an emergent recurring theme was the specific issue of the availability of suitable URLs (also referred to as domain names). This was mentioned by $50 \%$ of the participants as being a particular consideration they had to contend with, and was identified as being influential in their choice of company name. "In the digital age, it's finding something that's available in '.ie' or '.com' domain. So, we had some initial breakthroughs that I felt were great names and really worked and of course, the '.ie' or the 'com' names were gone".

In respect of the six criteria of memorability, meaningfulness, likability, transferability, adaptability and protectability, proposed by Keller for consideration when choosing brand elements, $90 \%$ of the participants described at least one of the six criteria when speaking of the particular circumstances around their own business; although only one interviewee listed more than one of the criteria. Overall, the six recommended criteria were acknowledged over the entirety of the ten interviews.

\subsection{Implementation of Brand Identity}

The third theme of the study sought to determine if an ongoing branding program is being applied and managed correctly by the firms interviewed, and in particular, how any internal and external brand communications were being implemented.

The study uncovered a rudimentary approach to internal brand building within each of the companies interviewed, with only $40 \%$ having any identifiable approach to internal brand communication. Of these, the processes for internal brand communication were poorly defined, with 2 of the 4 respondents quoting a semi-structured formal approach and the balance of the 4 taking an informal 'on the job' attitude. Of the remaining 60\%, it is relevant that $30 \%$ of the participant companies were at a stage where only the founders were employed and so there was no consideration of the topic, and while another $30 \%$ of the total admitted to having no approach to the topic, "there is no need to mention it", within this group, there were some who nonetheless recognised that it was an issue worth considering. "How do I make people feel they're part of something much bigger?" This study found a noticeable lack of commitment from the founder-owners towards a structured approach to internal brand identity building within each of their organisations. While there was some recognition of the importance of employee behaviour in contributing to the customers brand image, the evidence does not support a considered approach to this matter.

The findings show that the participant companies adopt a wide variety of external brand communication activities. Approximately 14 different activities were recorded, and these were classified under the headings of close and personal communication (face to face activities), e-communication (website, social media and electronic newsletters) and mass traditional communications. These findings are consistent with those of Bresciani and Eppler (2008) from a similar study of SMEs in Switzerland who found that "all of the examined start-up companies conduct a remarkable number of brand building activities; the individual mix of activities is however quite diverse" (2008: 360). This research finds that close \& personal and e-communication classifications had penetrated all companies extensively, with $100 \%$ of participants committed to both. A wide variety of mass communication vehicles are 
being used, although the most common vehicle of printed materials has only permeated $40 \%$ of participating companies. Some of these participants had also found additional brand communication methods through innovative use of packaging, secondary brand association opportunities and through the creative use of clothing rather than the adoption of branded uniforms. This correlates with the view of Gilmore et al., (1999) who content that "for SMEs, competitive advantage often has to be sought from other sources, or other ways of doing things" (1999: 33).

\subsection{Ongoing Evaluation and Maintenance of the Brand}

The fourth and final theme looked at whether the brand equity of each of the businesses being interviewed was being measured, evaluated and maintained correctly. For $90 \%$ of the interviewees, the responsibility for brand control lay with the owner, but all $90 \%$ admitted that they had no written brand control guidelines. "There's not that kind of traditional brand book". When it came to ongoing evaluation and maintenance, $70 \%$ were monitoring feedback from customers in a broad and unstructured manner which generally took the form of Facebook or face to face commentary. "I keep an eye on it through feedback and the way promotions are going and the general feedback from pop ups but I don't have any measured evaluation to judge that. I just use my own judgement". Only $10 \%$ of participants made use of any formal research to capture customer feedback. This took the form of a standard company survey, administered after the completion of the customer activities.

\section{Discussion}

The present work identified how only $30 \%$ of participants performed any formal sector analysis, merely $20 \%$ performed any competitive analysis and just $10 \%$ performed any strict customer analysis. Taken in totality, the findings offer an unfavourable picture of the level of strategic research undertaken by each of the interviewees in the early stages of their businesses. The lack of action on behalf of each of the founder-owners illustrates that a strategic analysis process was not considered as being of significant importance to these founder-owners during the early stage formation of their respective companies.

While many of the interviewees declare that they see branding to be important to their business, the evidence suggests that there is an indistinct command of what brand or branding truly means. The research fails to provide substantive evidence that any of the participants are fully engaged in the process of building a brand identity for their respective companies. The interviews undertaken and the subsequent analysis have created an unfavourable representation of the level of planning undertaken with regard to the building of the brand identity of each company. This is despite protestations as to its importance from many of the participants and an, admittedly, often tokenistic level of work which has been undertaken by them in this particular area. The results from this current study support the views of Wong and Merrilees (2005), who propose that SMEs believe in branding power, and demonstrate a certain level of interest in conducting branding activities in the future, if and when time and financial aspects allow them to do so, but "they are at this stage, pre-occupied with daily routine and business pitching" (2005:157). The impression formed was that each of the contributors was embroiled in day to day business activities, and that branding activities, 
even if they were being genuinely considered, were taking second place to ongoing day-to-day trading. "I guess the thing about most marketing companies is the adage of the cobbler's shoes that, once you get busy and up and running, you focus on working". Overall, the investigation identified how the founder-owners are all occupied in different brand building activities, but no company was found to have addressed the topic in a methodical manner consistent with that demanded by a theoretical model. Hence, it was not substantiated in the research that any of the participants are fully engaged in the process of building a brand identity for their respective companies.

While it is recognised that the success of an internal brand building program is dependent on leadership and the structural system in which it is placed (Vallaster \& de Chernatony, 2005:777), and that it is advisable not to keep the management of the brand to oneself, but instead communicate throughout the entire company how important it is (Krake, 2005: 235), the current study found a noticeable lack of commitment from the founder-owners towards an organised approach to internal brand identity building within each of their organisations. While there was some recognition of the importance of employee behaviour in contributing to the customers brand image, only $40 \%$ of the sample was demonstrated to have any form of approach to internal brand communication, and this was purely on an informal or semi-structured approach. Therefore the evidence does not support a considered approach to this matter.

On the matter of external communication, the results show that the companies interviewed utilise a wide variety of brand communication activities categorised as close and personal communication, e-communication and mass traditional communication. Indeed some of the participants had also found additional brand communication methods through innovative use of packaging, secondary brand association opportunities and through the creative use of clothing rather than adopting branded uniforms. Despite all of these efforts however, the research has uncovered a lack of broad and consistent activity on behalf of the participants across these major external communication platforms.

While the findings would appear to show some recognition on behalf of the founder-owners of the value of both internal and external communication, the research has failed to uncover an assiduous approach to both by those participants.

Finally, when it comes to ongoing evaluation and maintenance of their brands, only $10 \%$ of participants make any use of any formal research to capture customer feedback. For the vast majority of participants, the research uncovered a distinct lack of focus on behalf of the founder-owners towards a strict approach to ongoing evaluation and maintenance of their brands. These findings correlate with those of Bresciani and Eppler (2008) in their similar study of Swiss SMEs.

\subsection{An SME Brand Identity: Building a Model for Practice}

Based on the brand development steps for SMEs proposed by Ruzzier et al., (2013), and through the addition of a number of empirical recommendations, this current study has allowed the development of a suggested model for practice as follows (Fig.2): 


\section{Macrothink}

1. Prior to any brand development activities commencing, the founder-owner should ensure he/she has a satisfactory level of knowledge concerning all branding related issues outlined in this research. If this does not exist, further education, or training, should be sought in order to enhance their management skills in this area and to develop a more comprehensive understanding of the subject matter.

2. During the inception stage of the business, a full strategic analysis to include sector, customer, competitor and self-analysis should be completed, using the results of this analysis to frame the positioning for the business.

3. Identify the necessary brand identity elements including mission, vision, value, culture, distinguishing preferences, attributes, benefits\& personality. Document these for sharing amongst stakeholders.

4. Find the appropriate visual identity elements including name, logo, slogan, \& web domain. Apply the 6 elements of memorability, meaningfulness, likeability, transferability, adaptability, protectability (Keller, 2008). The findings of this study recommend the use of online marketplace expertise, which offers a viable and cost effective solution for SMEs as they progress through the various growth stages. Once these elements have been created, they should be protected, wherever practical.

5. Implement the brand internally within the organisation ensuring that any new staff members fit the desired culture and that all brand identity elements are communicated to them in full. This step must guarantee that they are in full alignment with the mission, vision and values of the company. Use a holistic approach to external brand communication to ensure a coherent brand image can be developed.

6. Measure and evaluate the results. It is important to measure the effect of branding efforts both internally and externally, and to take any necessary actions to improve performance. The branding process is cyclical and feedback must be incorporated. 


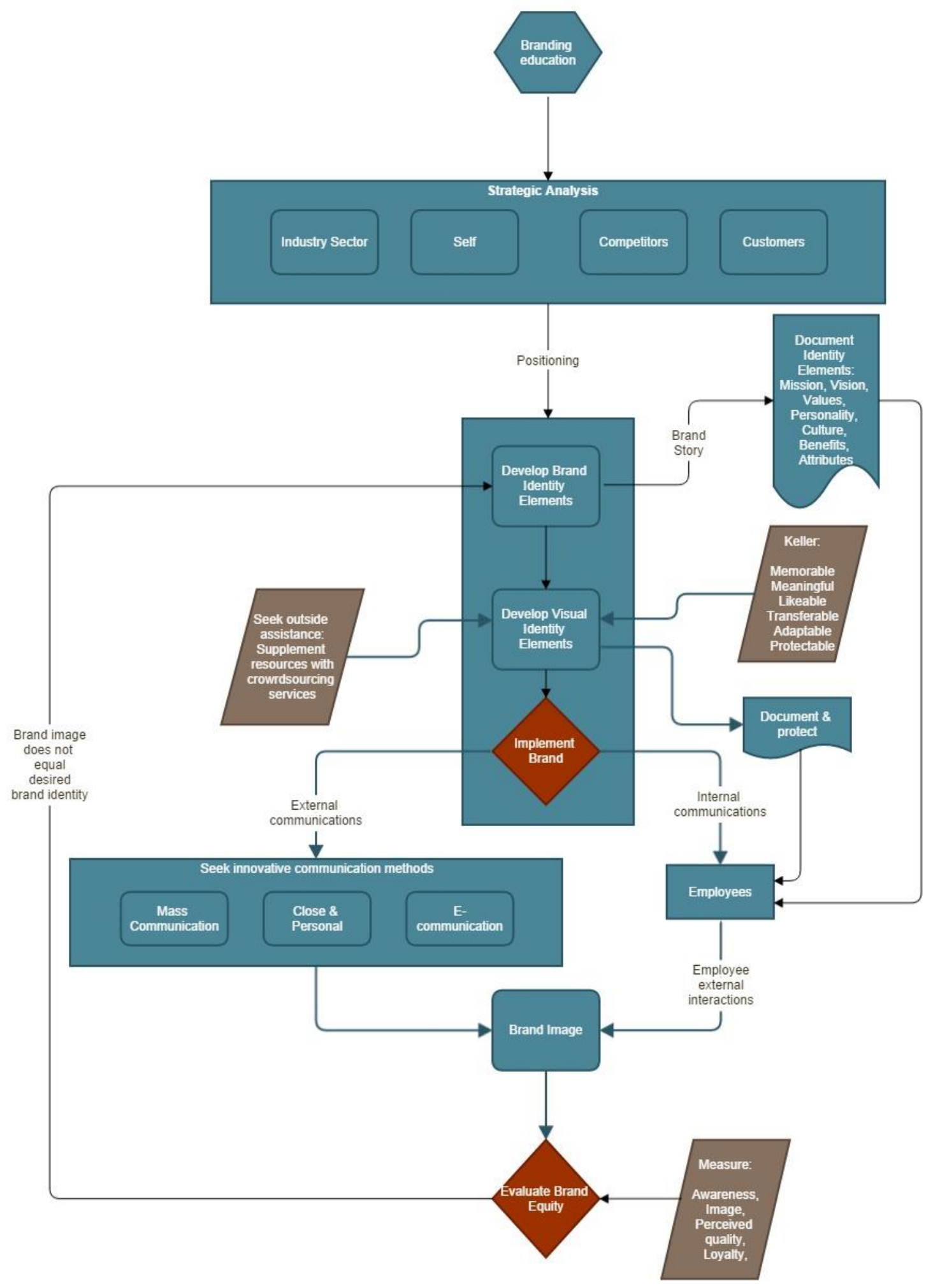

Figure 2. Brand identity building in SMEs: A model for practice

[Adapted from Ruzzier et al., (2013)]. 


\section{Recommendations}

Taken from both existing bodies of work and the new primary research performed as part of this study, in addition to the suggested model for practice, it has been possible to identify 11 practical recommendations for branding practice from which Irish start-up founders may benefit:

1. Founder-owners should proactively seek out instruction in the area of strategic brand management, and how to maximise the capabilities of low-budget, yet powerful branding tools such as online branding strategies, PR, guerrilla marketing, secondary associations and social media.

2. With this knowledge, they should take brand and branding into account at the pre-establishment stage of the business. They should also anticipate that the company may expand and build this assumption into the brand development process.

3. The founder should play a pivotal role in brand building. As an entrepreneur, they are the brand and they should embody it in everything they do to deliver the message as clearly as possible. This passion must be instilled in the entire organisation. Without the direction of the founder, an uncontrolled and likely undesired brand image will be established in the mind of stakeholders.

4. Strategic analysis is vital, and a full examination should be undertaken and led by the founder-owner. The company needs to understand who they are, why they exist and who the customer is.

5. Once strategic analysis is completed, use the information gathered as the foundation on which to build the brand identity elements. These elements are not fanciful. They represent the invisible part of the brand and form the foundation towards formulating the visible identity elements through which the consumer can better understand the brand.

6. Establish the visual identity elements, which should reflect the brand identity elements.

a. The owner should not undertake this task independently. Seek outside help to design these visual identity elements, which should incorporate the six recommendations laid down by (Keller, 2008). Web-based crowdsourced marketplace services mean that expert knowledge is now available for minimal investment. The founder-owner should familiarise themselves with these platforms and their capabilities.

b. The lack of availability of a web domain can influence the naming of a business and should be taken into account during the naming process.

c.If feasible, protect all visual elements. 


\section{Macrothink}

Business and Economic Research

ISSN 2162-4860

2016, Vol. 6, No. 1

7. Once brand identity elements and visual identity elements are defined they should be documented and shared amongst all stakeholders for consistency of future brand communication.

8. Employee behaviour and organisational culture impacts upon brand image, therefore, the brand should be communicated and implemented internally from the top down.

a.Recruit staff that fit the desired culture

b. Formally induct and train these staff on the corporate brand.

c.Make the documented guidelines for both brand identity elements and visual identity elements accessible to all employees.

9. Exploit all external brand communication opportunities to communicate the desired brand identity, and ensure branding is integrated across the entire marketing mix.

a.Close \& personal, for example, networking.

b. E-communication opportunities. A web-site with an appropriate domain name and relevant blog articles, \& continuous social media activity utilising the most appropriate channels for the business type, (such as, Facebook for B2C, and LinkedIn for B2B).

c.Leverage secondary associations as corporate brand image and identity is transferrable from stronger to weaker firms.

d. Be innovative with all branding opportunities. Printed materials and packaging will form a crucial part of the brand communication no matter what the business type.

10. Resources, including time and financial, must be made available for branding efforts. Investigate 'crowdsourcing' platforms which have the possibility to provide invaluable and inexpensive resources for SMEs.

11. Measurement is fundamental. Only if the brand performance is being measured can appropriate brand maintenance ensue.

\section{Recommendations for Future Research}

Research in the area of small business branding in an Irish context is virtually non-existent and thus provides a large field of opportunity for the performance of further research.

The empirical part of this study was based on 10 interviews of non-sector specific micro and small enterprises operating in both the B2B and B2C environments. It would be appealing to narrow the scope of this company selection and perform interviews in smaller sub-sectors of this current sample to see if any new information arises. For example, isolating specific business types, B2B vs B2C, or specific industry segments would both be relevant contexts for further research on this field.

Quantitative research methods could also be used to study a larger sample of respondents and 
case companies to form a richer understanding of the topic. A more accurate picture could be reached of the practices of the founder-owners with the use of a well-planned questionnaire and a much larger sample. More obvious connections between the growth stages and corporate brand building activities could also be established with the use of quantitative research methods. This study has been a valuable catalyst towards a discourse about the practices of small business owners in Ireland towards corporate brand building practices within their companies, and, based on this study, quantitative research could be carried out to further confirm the results.

The study specifically focuses on the Irish market. It would be possible to take the framework identified in this study, and apply it internationally. This would have the added benefit of allowing a new researcher to perform a comparative study between Ireland and other countries.

In general, by extending the limited available research on branding practices amongst Irish small and micro enterprises this study makes a contribution. However, there are many aspects which require further investigation. The results can provide direction for further research in this field of micro and small enterprise brand development. Moreover, answers to the aforementioned proposals could provide further insights into the development and management of brands within and external to the Irish SME environment.

\section{Conclusions}

The purpose of this research was to investigate and understand the practices of early-stage micro and small enterprises in Ireland and the approach of their founder-owners to the strategic brand management process.

Combining the results from each of the themes investigated, the researcher believes that amongst the target population in this study, knowledge of the topics of brand and brand building are at a low level. The research identifies that from the inception of the company strategic analysis is limited, there is an inconsistent approach to brand development, and ongoing branding programs could be planned better. Moreover, there are insufficient resources committed to internal and external brand implementation, and while some creativity towards more novel means of brand communication exists, this is not widespread. Finally, there is a lack of appreciation for the importance of ongoing formal evaluation and maintenance of the brands. In totality therefore, from an academic perspective, the study has provided a largely unfavourable picture of the branding practices of micro and small enterprises in Ireland, with a general lack of understanding and devotion on behalf of founder-owners towards the process being the main conclusion.

On the whole, the original objectives of the study were achieved. Clearer understandings of branding and the strategic brand management process as they apply to the target companies from both the perspective and the working traditions of the founder-owners were established. The research has improved the knowledge around the perception of founder-owners towards the relevance of branding within their companies, the brand creation processes they employ, the brand building activities in place within these companies, and the ongoing measurements 
of brand equity. In that regard, the study has supplemented the knowledge regarding the branding process in SMEs in Ireland and has contributed to the literature in this area. Through the identification of a new model for practice and 11 practical recommendations for branding practices for Irish start-up entrepreneurs, this study provides relevant contributions and suggestions. In the end, the results from this study also provide direction for further research in the field of micro and small enterprise brand development.

\section{References}

Aaker, D. A. (1996). Building Strong Brands. London: Simon and Schuster, 35, 68PMid:8877580

Aaker, D. A. (2014). Aaker on Branding: 20 principles that drive success. New York: Morgan James. 1, 25, 28, 231

Aaker, D. A., \& Joachimsthaler, E. (2009). Brand leadership. London: Simon and Schuster. pp.ix, 17, 25, 26, 27, 43, 44, 54 88. PMCid:PMC2783839

Abimbola, T. (2001). Branding as a competitive strategy for demand management in SMEs. Journal of research in marketing and entrepreneurship, 3(2), 97-106. http://dx.doi.org/10.1108/14715200180001480

Abimbola, T. (2010). Brand strategy as a paradigm for marketing competitiveness. Journal of Brand Management, 18(3), 177-179. http://dx.doi.org/10.1057/bm.2010.48

Abimbola, T., \& Kocak, A. (2007). Brand, organization identity and reputation: SMEs as expressive organizations: A resources-based perspective. Qualitative Market Research: An International Journal, 10(4), 416-430. http://dx.doi.org/10.1108/13522750710819748

Adamson, A. P. (2006). BrandSimple: how the best brands keep it simple and succeed. New York: Palgrave Macmillan. xvii, 3, 18,19, 221, 226.

Ahonen, M. (2008). Branding-does it even exist among SMEs. Proceedings of the 16th Nordic Conference on Small Business Research.

Beverland, M., Napoli, J., \& Yakimova, R. (2007). Branding the business marketing offer: exploring brand attributes in business markets. The Journal of Business and Industrial Marketing, 22(6), 394-399. http://dx.doi.org/10.1108/08858620710780154

Birdthistle, N., Hynes, B., Costin, Y., \& Lucey, S. (2010). The behavioural traits and characteristics of high and low expectation growth entrepreneurs: Is there a difference? Irish Business Journal, 6(1), 5-29.

Bresciani, S., \& Eppler, M. J. (2010). Brand new ventures? Insights on start-ups' branding practices. Journal of Product \& Brand Management, 19(5), 356-366. http://dx.doi.org/10.1108/10610421011068595

Dunn, M., \& Davis, S. (2002). Building the brand driven business. San Francisco: Jossey-Bass. 17, 196. 
European Commission, (2003). Commission Recommendation concerning the definition of micro, small and medium-sized enterprises, 2003 O.J. (L 124) 36, available at http://eur-lex.europa.eu/LexUriServ/LexUriServ.do?uri=OJ:L:2003:124:0036:0041:en:PDF (Accessed 30 of March 2014)

European Commission, (2005). The new SME definition-user guide and model declaration,

European Commission, (2006). Management Capacity Building, available at http://ec.europa.eu/enterprise/policies/sme/files/support_measures/mcb/mcb_en.pdf (Accessed 30 of March 2014)

European Commission, (2013). SBA Fact Sheet Ireland, available at http://ec.europa.eu/enterprise/policies/sme/facts-figures-analysis/performance-review/files/co untries-sheets/2013/ireland_en.pdf (Accessed 30 of March 2014).

Freiling, J., \& Laudien, S. M. (2013). Explaining new venture failure: A competence-based approach. In AIMS 2013 Conference, available at http://cdiaims2013.sciencesconf.org/conference/cdiaims2013/pages/cdiaims2013_Freiling_L audien.pdf (Accessed 06 April 2014).

Gilmore, A., Carson, D., O'Donnell, A., \& Cummins, D. (1999). Added Value: A qualitative assessment of SME marketing, Use Licence, 12(1), 27-35

Harris, F., \& de Chernatony, L. (2001). Corporate branding and corporate brand performance. $\begin{array}{lllll}\text { European } \quad \text { Journal } & \text { Marketing } & \text { 35(3/4): }\end{array}$ http://dx.doi.org/10.1108/03090560110382101

Hatch, M. J., \& Schultz, M. (2001). Are the strategic stars aligned for your corporate brand? Harvard Business Review, 4(1), 129-134.

Hatch, M. J., \& Schultz, M. (2003). Bringing the corporation into corporate branding. European Journal of Marketing, 37(7/8), 1041-1064. http://dx.doi.org/10.1108/03090560310477654

Hynes, B., \& Richardson, I. (2007). Entrepreneurship education: A mechanism for engaging and exchanging with the small business sector. Education+ Training, 49(8/9): 732-744.

Ibrahim, A. B., \& Soufani, K. (2002). Entrepreneurship education and training in Canada: a critical assessment. Education+ Training, 44(8/9): 421-430.

Inskip, I. (2004). Corporate branding for small to medium-sized businesses-A missed opportunity or an indulgence?. The Journal of Brand Management, 11(5), 358-365. http://dx.doi.org/10.1057/palgrave.bm.2540181

Juntunen, M., Saraniemi, S., Halttu, M., \& Tähtinen, J. (2010). Corporate brand building in different stages of small business growth. Journal of brand Management, 18(2), 115-133. http://dx.doi.org/10.1057/bm.2010.34

Keller, K. L. (2008). Strategic Brand Management. NJ:Pearson Prentice Hall. 2, 9, 38-40, 51, 140, 145, 147, 220, 289. PMid:18822146 PMCid:PMC2547861 
Kotler, P., Keller, K. L. (2007). Marketing Management. NJ:Pearson Prentice Hall. pp. 5, 3, 16,139

Krake, F. B. (2005). Successful brand management in SMEs: a new theory and practical hints. Journal of Product \& Brand Management, 14(4), 228-238. http://dx.doi.org/10.1108/10610420510609230

Lamons, B. (2005). The case for B2B branding. Mason, OH: Thomson South-Western. pp. 5, 7, 31, 73 .

Merrilees, B. (2007). A theory of brand-led SME new venture development. Qualitative Market Research: An International Journal, 10(4), 403-415. http://dx.doi.org/10.1108/13522750710819739

Mitchell, R., Hutchinson, K., \& Bishop, S. (2012). Interpretation of the retail brand: an SME perspective. International Journal of Retail \& Distribution Management, 40(2), 157-175. http://dx.doi.org/10.1108/09590551211201883

Ries, A., \& Ries L. (2002). The 22 immutable laws of branding. New York: Harper Collins. pp. ix,xii

Rode, V., \& Vallaster, C. (2005). Corporate branding for start-ups: the crucial role of entrepreneurs. Corporate Reputation Review, 8(2), 121-135. http://dx.doi.org/10.1057/palgrave.crr.1540244

Ropega, J. (2011). The reasons and symptoms of failure in SME. International Advances in Economic Research, 17(4), 476-483. http://dx.doi.org/10.1007/s11294-011-9316-1

Ruzzier, M. K., Ruzzier, M., \& Hisrich, R. D. (2013). Marketing for Entrepreneurs and SMEs: A Global Perspective. Cheltenham: Edward Elgar Publishing. 4, 7, 166-181

Sandbacka, Jenny, Satu Nätti, \& Jaana Tähtinen. (2013). Branding activities of a micro industrial services company. Journal of Services Marketing, 27(2), 166-177. http://dx.doi.org/10.1108/08876041311309270

Saunders, M., Lewis, P. \& Thornhill, A. (2007). Research Methods for Business Students. (4th ed.) Harlow: FT/Prentice Hall. pp. 102-104, 108, 117, 133, 135, 142, 145, 312-313, 318, $324,334,475,478-479,499,505$

Vallaster, C., \& de Chernatony, L. (2006). Internal brand building and structuration: the role of leadership. European Journal of Marketing, 40(7/8), 761-784. http://dx.doi.org/10.1108/03090560610669982

Wisker, G. (2008). The postgraduate research handbook: Succeed with your MA, MPhil, EdD and PhD. Palgrave Macmillan. 67, 68, 71-73, 214, 75.

Wong, H. Y., \& Merrilees, B. (2005). A brand orientation typology for SMEs: a case research approach. Journal of Product \& Brand Management, 14(3), 155-162. http://dx.doi.org/10.1108/10610420510601021 


\section{Copyright Disclaimer}

Copyright for this article is retained by the author(s), with first publication rights granted to the journal.

This is an open-access article distributed under the terms and conditions of the Creative Commons Attribution license (http://creativecommons.org/licenses/by/3.0/). 